\title{
A Method for Identifying Abnormal Operation State of Variable Pitch System of Wind Turbine
}

\author{
Yang Jinpeng $^{1}$ Wang Jianming $^{2}$ Yao Wanye ${ }^{1}$ \\ ${ }^{1}$ Department of automation, North China Electric Power University, hebei baoding \\ 071003, China \\ ${ }^{2}$ ZhongHengBoRui,xierqi street,Haidian district,Beijing city,China \\ 1yang445226@sina.cn
}

\begin{abstract}
Keywords: curve fitting;health model;residual mean;sliding window
Abstract: From the analysis and arragment of historical data of wind turbine pitch motor temperature、wind speed and other related parameters of hebei chigu wind farm in 2015 ,the paper obtains historical data using 10 minutes as acquisition unit under various operating conditions of wind turbine pitch system from SCADA system,puts forward a method that establish a health model of the operation of variable pitch system using the method of piecewise polynomial curve fitting,then predict the change trend of the parameters of real time condition according to this health model and judge the residual error between actual value and predicted value based on the method of sliding window residual mean.Finally identify the abnormal operation condition of the variable pitch system combined with practical experience in the field.Verified by historical data,this method can findout the abnormal state of variable pitch system in time and make accurate judgment so as to eliminate the hidden trouble.It has a high practical value for the economic operation.to wind field.
\end{abstract}

\section{I .Introduction}

With the development of wind power industry, the scale of wind farm is increasing.Most of the wind farms are bulit in gobi, grassland, beaches, islands, mountains and coastal areas. Though these areas are rich in wind resources but far away from the center of city,the operating environment of wind turbine is rather adverse.The areas of northeast china are especially vulnerable to frost, snow storm, dust storm. The erosion of equipment is serious in some areas,ice and snow in winter also has great influence on the stable operation of the equipment.In view of such a bad environment.The complex of wind speed and direction,as well as the over-changing of environment temperature increase will lead frequent fan failure.It is urgent to know about the running state of fan in real time because of the huge cost of fault diagnosis and maintenance ,as well as mass loss of generating capacity.

The majority of domestic wind field installed megawatt VSCF wind turbine,in order to adapt to different conditions,such as different wind levels and ambient temperatures,most models of wind turbine use variable pitch control technology. As the key component of pitch control device,variable pitch motor plays an important role in the pitch control of wind turbine.Complex working conditions and highly frequent load change will bring great damage to the variable propeller motor.If the operating conditions of wind turbine can be accurately evaluated,then plan the arrangement of operation and maintenance reasonably for wind turbine,it will make a great sense to prolong the life of wind turbine, avoiding serious trouble and save maintence cost.

\section{II.Variable pitch system evaluation system}

Variable pitch system is an important part of fan,its components are shown in figure 1.The main function of this device is that when the wind speed is less than the rated speed,change the pitch angle through the pitch system so as to improve the absorption coefficient of wind energy Cp and ensure the maximum efficiency of absorption of wind energy,when the wind speed is higher than rated speed,reduce fan speed by adjusting pitch angle,maintaining the output power of wind 
turbine in the vicinity of rated value so as to prevent the overload of generator and inverter system and ensure the normal and stable operation of fan.

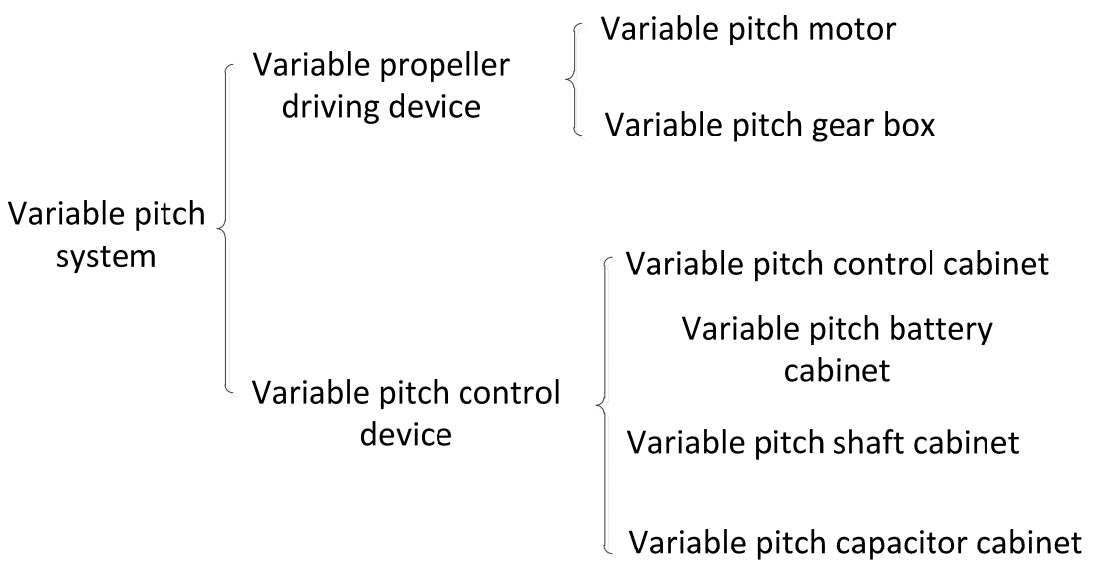

Figure 1 Components of variable pitch system

Due to the uncertainty and the characteristics of sudden change of wind,variable pitch acts frequently,it is very easy to cause the damage of the propeller device.From the statistics 732 times pitch system fault of hebei chi Gu wind field in 2015,the damage of the components is shown in table 1:

Table 1 Statistics table of fault of the pitch control system

\begin{tabular}{ccc}
\hline Name of failue & Times & Cause analysis \\
\hline $\begin{array}{c}\text { Temperature limitation } \\
\text { of motor is exceeded }\end{array}$ & 412 & $\begin{array}{c}\text { Sudden change of wind 、 act } \\
\text { frequently ambient temperature }\end{array}$ \\
$\begin{array}{c}\text { Temperature limitation } \\
\text { of contol cabinet is exceeded } \\
\text { Voltage limitation of }\end{array}$ & 135 & Line problem of variable pitch \\
$\begin{array}{c}\text { contol cabinet is exceeded } \\
\text { other }\end{array}$ & 117 & Line problem of variable pitch \\
\hline
\end{tabular}

From the table,it is known that more than $50 \%$ of the faults occurred in variable pitch motor in 2015.The temperature of rotor winding is used as a key point to evaluate the running state of variable pitch system according to the working principle.

\section{III.Establishment of "health model" of variable pitch system}

In order to fit the operating conditions of variable pitch system,it is necessary to arrage and analysis the historical data of the same type wind turbine for a long period in the wind field so as to simulate a more complete health mode.There are certain quality requirements for the data.The selection principles of the sample data are as follows:

1) The data sample is derived from the conditon that the fan run normally,namely the wind speed is between $3 \mathrm{~m} / \mathrm{s}$ and $15 \mathrm{~m} / \mathrm{s}$.

2) Sample data must be taken from the steady running condition of fan,

In view of the above principles,select the pitch motor winding temperature data base of hebei chigu wind farm in 2015 year as the sample source. Take 10 minutes as the acquisition unit,get the average value of 10 minutes of winding temperature of variable pitch motor from the field SCADA system.Through the statistical analysis of massive historical data,select $0.5 \mathrm{~m} / \mathrm{s}$ as wind speed division unit based on IEC standard. The statistics of the steady state operation of variable pitch system are shown as table 2:

Table 2 steady state condition of variable pitch system

\begin{tabular}{llllllllllll}
\hline $\begin{array}{l}\text { Number of } \\
\text { conditions }\end{array}$ & 1 & 2 & 3 & 4 & 5 & 6 & 7 & 8 & 9 & 10 & 11 \\
\hline
\end{tabular}




\begin{tabular}{|c|c|c|c|c|c|c|c|c|c|c|c|}
\hline $\begin{array}{l}\text { Wind speed } \\
\qquad(\mathrm{m} / \mathrm{s})\end{array}$ & 4 & 4.5 & 5 & 5.5 & 6 & 6.5 & 7 & 7.5 & 8 & 8.5 & 9 \\
\hline $\begin{array}{l}\text { Temperature of } \\
\text { variable pitch } \\
\text { motor }\left({ }^{\circ} \mathrm{C}\right)\end{array}$ & 57 & $\begin{array}{c}58 . \\
2\end{array}$ & $\begin{array}{l}5 \\
9\end{array}$ & 59.7 & 61 & 62 & 62.3 & 63 & 63.7 & 64 & 64.2 \\
\hline $\begin{array}{l}\text { Number of } \\
\text { conditions }\end{array}$ & 12 & 13 & 14 & 15 & 16 & 17 & 18 & 19 & 20 & 21 & 22 \\
\hline $\begin{array}{c}\text { Wind speed } \\
(\mathrm{m} / \mathrm{s})\end{array}$ & $\begin{array}{l}9 . \\
5\end{array}$ & 10 & 10.5 & 11 & 11.5 & 12 & $\begin{array}{r}12 \\
5\end{array}$ & 13 & $\begin{array}{c}13 . \\
5\end{array}$ & 14 & 14.5 \\
\hline $\begin{array}{l}\text { Temperature of } \\
\text { variable pitch } \\
\text { motor }\left({ }^{\circ} \mathrm{C}\right)\end{array}$ & 64 & $\begin{array}{c}64 . \\
3\end{array}$ & 64.2 & 64 & 63.8 & 64.1 & 64 & 65 & $\begin{array}{c}64 . \\
7\end{array}$ & $\begin{array}{c}64 . \\
5\end{array}$ & 64.2 \\
\hline
\end{tabular}

For temperature index,make the index curve based on the bin method of IEC standard,then the fitting function of temperature change with wind speed is obtained by curve fitting. The curve of wind speed vs temperature of variable pitch motor is shown in figure 2:

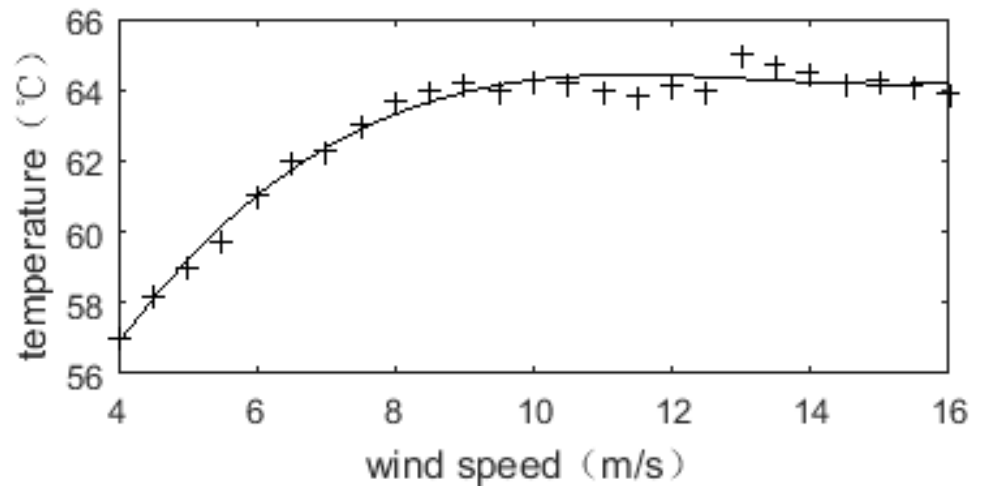

Figure 2 Variable pitch motor winding temperature curve

Thus,the polynomial fitting function of winding temperature of variable pitch motor vs wind speed can be expressed by the expression 1 :

$$
T(w)=\left\{\begin{array}{l}
57 ; w \leq 4 \\
0.0107 w^{3}-0.4236 w^{2}+5.5033 w+40.9481 ; 4 \prec w \prec 12 \\
64 ; 12 \leq w \leq 16
\end{array}\right.
$$

In the above formula, $\mathrm{T}(\mathrm{w})$ is the theorial calculation value of stable operation condition of variable pitch system, $\mathrm{w}$ is wind speed.

\section{IV.Residual analysis}

During running condition, owing to the existence of uncertainty and random interference,the actual value and predicted value of winding temperature of variable pitch motor will be a certain deviation leading to the emergence of some isolated points.In addition,the value and time of grid connected power can also affect the winding temperature of variable pitch motor.

The historical data of wind field are verified by the method of residual analysis,.ake 10 minutes as the acquisition unit,select historical data of winding temperature of variable pitch motor between April 9, 2015,14:30:00 and April 15th from SCADA system to verify the "health model",the residual error is shown in figure 3 : 


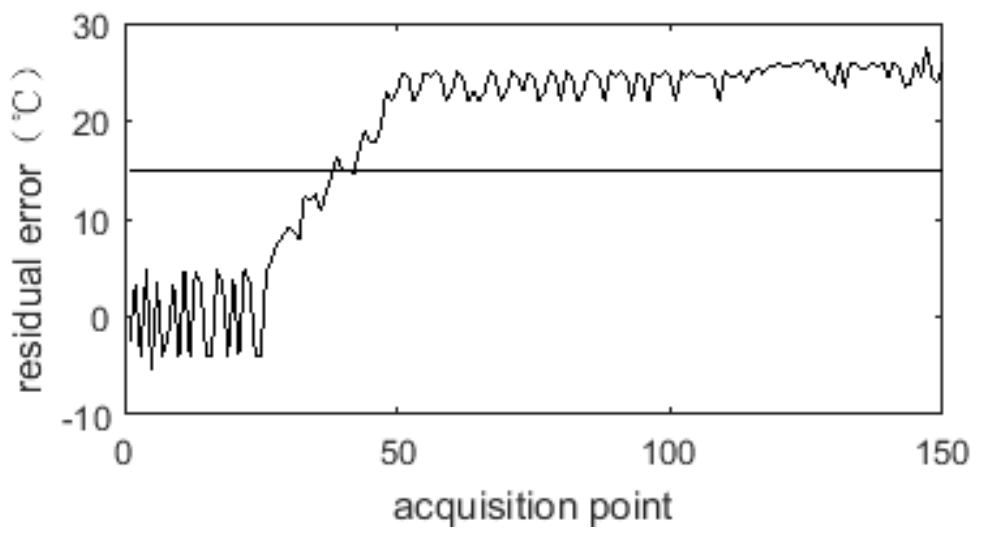

Figure 3 residual error figure

From the image above,it is known that between the first 0 25 acquisition points,temperature residual is kept in a stable range and has a large margin to the warning threshold. It begins to increase rapidly from about 30 acquisition point,the temperature exceeds the threshold and continues to increase.Thus, the abnormal condition of pitch control system may occur between the 25 30 acquisition points.Query historical fault list of SCADA system,the result is shown in table 3 as follows:

Table 3 record information of SCADA system

\begin{tabular}{cccc}
\hline Time & $\begin{array}{c}\text { Sampling } \\
\text { point }\end{array}$ & Residual & Reason \\
\hline $2015 / 4 / 11$ & 26 & 11.5 & \\
$05: 20: 00$ & 27 & 14.3 & Failure of variable pitchr cooling \\
2015/4/11 & & & fan \\
$05: 30: 00$ & 28 & 13.6 & \\
$2015 / 4 / 11$ & 29 & 14.8 & Variable pitch motor winding \\
$05: 40: 00$ & 55 & 21.4 & temperature limit warning \\
$2015 / 4 / 11$ & & &
\end{tabular}

\section{V.Summary}

The result combined with the residual diagram and SCADA record information diagram shows that calculating the change trend of winding temperature of variable pitch based on the method of historical data fitting curve analysis is able to predict the overall change trend.Judge the residual value between actual value and predicted value based on the sliding window analysis method,then set up early warning threshold according to field experience.This method can findout the abnormal condition of pitch control system in time and make an accurate judgment.It shows that this method have high applicable value.

\section{Reference}

[1] Gu Yutong,SuLuwei,Zhong Yang,Xu Ting,Online fault early warning method for wind power gear box based on interval division[J], Electric power science and Engineering;North China Electric Power University press,2014,8

[2]Wu Huirong.Statistical principle[M],Shanghai:Press of Shanghai Jiaotong University ,2000.

[3] Zhu Yonghua.Learning Guidance of Application of statistical[M].Wuhan:Press of wuhan University,2002. 
[4] GB/T 4883-2008,The statistical processing of data and the judgement and treatment of the outliers of normal sample[S].

[5]GaoXiangbao,DongLingqing.Mathematical analysis and SPSS application[M].Beijing:press of Tsinghua University,2007.

[6] Xiao Yunqi,Wang Kunming,He Guanju,Sun Yanping,Yang Xiyun;Fuzzy comprehensive evaluation of operation state of large wind turbine based on trend prediction,Proceedings of the CSEE,2014,5. 